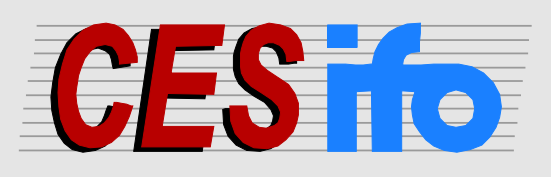

\title{
Working
}

Papers

www.cesifo.org/wp

\section{Tax Base Erosion and Inequity from Michigan's Assessment Growth Limit: The Case of Detroit}

\author{
Timothy R. Hodge \\ Mark Skidmore \\ Gary Sands \\ Daniel McMillen
}

CESIFO WORKING PAPER NO. 4098

CATEGORY 1: Public FinANCE

JANUARY 2013

An electronic version of the paper may be downloaded

- from the SSRN website: $\quad$ www.SSRN.com

- from the RePEc website: $\quad$ www.RePEc.org

- from the CESifo website: www.CESifo-group.org/wp

\section{CESifo}




\title{
Tax Base Erosion and Inequity from Michigan's Assessment Growth Limit: The Case of Detroit
}

\begin{abstract}
In this paper we examine the degree to which Michigan's property value assessment growth cap has eroded the tax base and created substantial differences in effective tax rates among residential properties within the City of Detroit. While the analysis focuses on a specific city with significant tax base erosion challenges, it is relevant to other cities in Michigan and across the nation, particularly in states that impose assessment growth limits. Using quantile regression techniques, we examine how an assessment growth cap alters effective tax rate distributions within and across property value groups. Results show that the cap creates a wide range of effective tax rates across properties of similar value (horizontal inequity), and similar tax payments for properties of differing values (vertical inequity).
\end{abstract}

JEL-Code: H710.

Keywords: property tax, assessment growth limit, equity, quantile regression.

Timothy R. Hodge
Dept. of Agricultural, Food, and Resource
Economics / Michigan State University
125 Cook Hall
USA - East Lansing, MI 48824
hodgetim@msu.edu
Gary Sands
Urban Planning Program
Wayne State University
1051 Hartsough Street
USA - Plymouth, MI 48170-2143
gary.sands@wayne.edu

\author{
Mark Skidmore \\ Dept. of Agricultural, Food, and Resource \\ Economics \& Dept. of Economics \\ Michigan State University \\ 91 Agriculture Hall \\ USA - East Lansing, MI 48824 \\ mskidmor@msu.edu
}

\author{
Daniel McMillen \\ Department of Economics, IGPA \& \\ Department of Economics (MC 037) \\ University of Illinois \\ 1007 W. Nevada St. \\ USA - Urbana, IL 61801 \\ mcmillen@illinois.edu
}

January 15, 2013

We thank the Lincoln Institute of Land Policy for financial support. We thank Fred Morgan of the City of Detroit Assessment Division for providing detailed parcel level data, and Councilman Kenneth Cockrel for inviting us to work on this issue. 


\section{INTRODUCTION}

Over the past 20 years, the landscape of Michigan's residential property tax has undergone various changes. New policies have been enacted statewide to reduce tax payments and mitigate large year-over-year changes, including the property value assessment growth cap ${ }^{5}$ and the Principal Residence Exemption. In addition, targeted tax abatements such as the Neighborhood Enterprise Zone and Renaissance Zone programs have been implemented locally in an effort to stimulate economic development. Regardless of the intended outcomes, these policies have resulted in considerable tax base erosion. The Michigan Department of Treasury (2010) estimates that the revenue loss from the taxable value cap, Principal Residence Exemption, and property tax abatement programs was more than $\$ 7$ billion statewide in 2010. Of these policies, this paper focuses primarily on the assessment growth limit because it affects all Michigan property owners and is one of the largest tax expenditures.

Michigan's assessment growth cap was part of Proposal A, a sweeping education finance reform that was approved by referendum in $1994 .{ }^{6}$ Prior to the passage of Proposal A, property taxes were based on the state equalized value (SEV) of property. ${ }^{7}$ After 1994, the growth of residential property values for tax purposes was limited to the lesser of the rate of inflation multiplier or 5 percent, regardless of any increase in the property's SEV. ${ }^{8}$ Thus, in a market where housing prices are growing more quickly than the general price level, the growth in

\footnotetext{
${ }^{5}$ We refer use the following phrases interchangeably throughout the text: assessment growth cap, taxable value cap, assessment growth limit.

${ }^{6}$ For an extensive review of Proposal A, see Feldman, Drake, and Courant (2003).

${ }^{7}$ A property's state equalized value is equal to 50 percent of the assessed market value (or true cash value) of the property. In Michigan, the SEV of each property in a jurisdiction is determined by December 31 of the previous year.

${ }^{8}$ Each year the Michigan Department of Treasury's Tax Analysis Division calculates the rate the inflation multiplier using data from the Bureau of Labor Statistics. Since the passage of Proposal A, the growth in taxable value has been restricted solely by the calculated rate since it has been less than 5 percent each year.
} 
taxable value (TV) of a property will lag behind growth in SEV. ${ }^{9}$ However, Proposal A also specifies that the taxable value of a property return to its current market-based SEV whenever a property is sold or transferred. ${ }^{10}$ The effective property tax rate of each homeowner is therefore a function of the changes in property value, the rate of inflation, and the owner's length of residence.

Michigan's approach to mitigating large year-over-year changes to residential tax payments by limiting the growth of property assessments is not unique. Haveman and Sexton (2008) identify at least 20 states that have assessment growth limitations similar to Michigan's. The body of research examining the consequences of assessment growth limits is growing. The early empirical work focused on determining the degree to which these fiscal institutions constrained property tax revenue growth (Dye, McGuire, \& McMillen, 2005; Skidmore, 1999). More recently, researchers have turned their attention to assessing how property tax limits create inequity among property owners (Dye, McMillen, \& Merriman, 2006; Minnesota Department of Revenue, 2007; Muhammad, 2007; Skidmore, Ballard, \& Hodge, 2010). In the context of property taxation, horizontal inequity occurs when effective tax rates vary between houses with similar market values. Vertical inequity occurs when effective tax rates are differ across a range of market values; that is, higher valued properties do not always pay more taxes than lower valued properties (Muhammad, 2007).

A primary contribution we make to the existing literature is the use of quantile regression techniques to assess the inequities resulting from the taxable value cap. Standard regression analysis is not necessarily the most suitable approach for evaluating the equity implications of

\footnotetext{
${ }^{9}$ The gap between the TV and SEV will diminish in a housing market where SEV is stable or declining. The TV (and tax payment), however, may continue to increase until the taxable value equals the state equalized value.

${ }^{10}$ This "pop up" effect includes the transfer of property from one family member to another.
} 
policies because such analysis is based on central tendencies. As we discuss in detail later, the quantile regression technique reveals how property tax policies affect the entire distribution of effective tax rates within and across property value classes, which offers a much richer and more complete evaluation. This approach also reveals the sources of the average effects captured with standard regression analysis- whether the effect is the result of a location shift (i.e. a change in mean value), a scale shift (i.e. a change in the variance), or both. Our findings provide a more complete understanding of the effects of these policies and thus may encourage policymakers to more seriously consider systemic changes toward a more coherent, efficient, and equitable property tax system.

In the next section, we provide a description of the property tax environment in Michigan and Detroit. In Section 3, we review earlier research regarding property value assessment growth limits and the effect of such limits on property tax equity. The empirical strategy for measuring the determinants of effective tax rates across parcels in Detroit is discussed in Section 4. The data and estimation results are presented in Sections 5 and 6, respectively. Finally, we provide concluding remarks in Section 7.

\section{THE PROPERTY TAX IN MICHIGAN AND DETROIT}

The statewide average statutory property tax millage rate in 2009 was 39.13 mills (Michigan Taxpayer's Guide, 2011). ${ }^{11}$ However, as highlighted by Skidmore, Ballard, and Hodge (2010), the statutory property tax rate varies substantially from one jurisdiction to another. Detroit taxpayers in particular face statutory millage rates that are much higher than the statewide average; the total 2010 millage rate for owner-occupied residential properties was 66.61 mills (Table 1). This high tax burden is, to some degree, alleviated for some longtime

\footnotetext{
${ }^{11}$ One mill is defined as $\$ 1$ due in taxes per $\$ 1,000$ of the property's taxable value.
} 
homeowners because effective tax rates are reduced as a result of Proposal A, and other homeowners may enjoy reduced effective tax rates as a result of various abatement programs.

Table 1: Owner-Occupied Residential Millage Rates in Detroit (2010)

\begin{tabular}{|l|c|l|c|}
\hline \multicolumn{1}{|c|}{$\begin{array}{l}\text { Mummer Taxes } \\
\text { Taxing Authority }\end{array}$} & $\begin{array}{c}\text { Winter Taxes } \\
\text { Mills }\end{array}$ \\
\hline State Education & 6.0 & County Operating & 0.98 \\
General City Operating & 19.95 & Wayne County Jail & 0.93 \\
Debt Service (City) & 8.91 & Wayne County Parks & 0.24 \\
Library & 4.63 & HCMA** & 0.21 \\
School Bond Debt & 13.0 & Wayne County RESA*** & 0.09 \\
School Operating & N/A* & Wayne County RESA Sp. Ed. & 3.36 \\
School Judgment & 0.1 & Wayne County CCD**** & 2.47 \\
Wayne County Operating & 5.64 & Wayne County Zoo & 0.1 \\
\hline Total Summer & $\mathbf{5 8 . 2 3}$ & Total Winter & $\mathbf{8 . 3 8}$ \\
\hline *Not applicable to owner-occupied residential properties (see Proposal A discussion below). \\
**HCMA - Huron Clinton Metropolitan Authority \\
***Intermediate School District \\
****Community College
\end{tabular}

\section{Proposal A}

The adoption of education finance reform implemented with the passage of Proposal A in 1994 was designed to reduce Michigan's dependence on property taxation as well as the substantial disparities in school district spending. Prior to 1994, Michigan public schools were financed almost exclusively through school district property taxation, resulting in a high reliance on property taxes and substantial differences among school districts in expenditures per student. These features were the source of considerable dissatisfaction among voters, which led to the reforms. ${ }^{12}$ A key feature of Proposal A that is of relevance to the present study is that it limited the annual increases in taxable values to the rate of inflation or five percent, whichever is less.

\footnotetext{
${ }^{12}$ See Feldman, Drake, and Courant (2003) for a detailed discussion of the reforms.
} 
This provision provided tax relief to homeowners who were experiencing higher than average rates of property value growth within their jurisdiction.

Along with the taxable value cap, Proposal A also reduced the statutory property tax rate of owner-occupied properties and modified school spending by introducing a distinction between "homestead property" and "non-homestead property." A homestead is defined as the homeowner's principal residence. Specifically, Proposal A exempts qualified homestead properties from paying the public school operating millage, whereas for non-homestead properties Proposal A limits the statutory millage rate to 18 mills. Statutory millage rates were reduced by an average of about one-third statewide as a result of the homestead exemption. This reduction in millage rates varied across jurisdictions; in 2010, homestead properties in the City of Detroit, where tax rates are particularly high, received a 17.83 mill reduction in their statutory rate (a 21 percent decrease).

To replace revenue lost from the homestead exemption and provide funding for elementary and secondary education, a 6-mill "state education tax" was imposed in all jurisdictions and both the sales tax and cigarette tax were increased. This new formula for school funding centralized school financing and reduced the variability in per-pupil expenditures school districts. However, despite these changes considerable differentials remain between the highest and lowest spending districts.

The Michigan Department of Treasury (2010) provides annual estimates of tax expenditures for all major sources of tax revenue. In 2010, the total revenue loss from the taxable value cap was $\$ 3.4$ billion, second only to the homestead exemption, which produced an estimated revenue loss of $\$ 3.52$ billion. Focusing on Detroit, Figure 1 highlights the divergence between TV and SEV since 1994. As shown in Figure 1, SEV grew faster than TV from 1994 
through 2003, and then they grew about the same rate through 2006. The largest differential between TV and SEV occurred in 2003 when taxable value was about $65 \%$ of state equalized value. However, beginning in 2006 the difference began to narrow, and by 2011 TV was $86.5 \%$ of SEV.

Figure 1: Detroit Residential SEV vs. TV

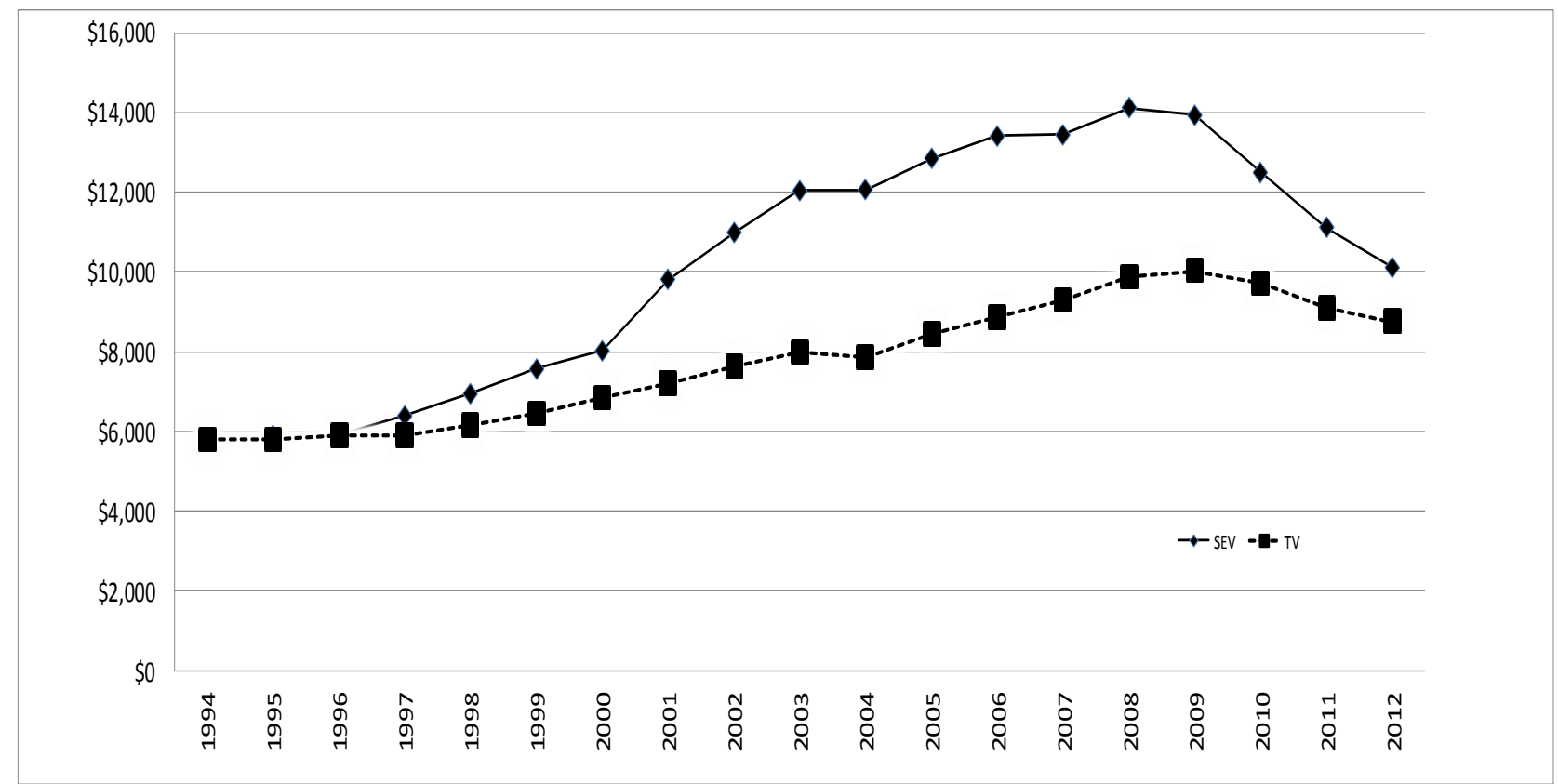

Dollar figures in millions.

Source: Source: City of Detroit Comprehensive Annual Financial Reports

\section{$\underline{\text { Abatement Programs }}$}

In addition to the inequities stemming from the assessment growth limit, we also consider Detroit's abatement programs in order to accurately measure effective tax rates and isolate the effect of the assessment growth cap on horizontal and vertical equity. Two programs offered in Detroit include Neighborhood Enterprise Zones (NEZ) (PA 147 of 1992) and Renaissance Zones (RZ) (PA 376 of 1996). Under the Neighborhood Enterprise Zone program, three different property tax reductions are available to residential property owners in economically distressed 
communities who develop or rehabilitate residential housing: Rehabilitation (NEZR), New $(\mathrm{NEZN})$, and Homestead $(\mathrm{NEZH}) .{ }^{13}$ Substantial rate reductions are offered under both NEZ and RZ programs; a more detailed explanation of these programs is provided in Appendix $1^{14}$, and Table 2 provides a summary of the millage rates for each type of abatement. In addition, Table 2 provides the estimated tax payment for a property with an assessed land value equal to $\$ 20,000$ and an improvement equal to $\$ 40,000$. The tax payment column provides a sense of the savings that accrue to beneficiaries for each type of abatement. ${ }^{15}$ Figure $2^{16}$ shows the locations of the Neighborhood Enterprise Zones and the Renaissance Zones in Detroit.

Table 2: Summary of Millage Rates for Owner-Occupied Residential Property in Detroit

\begin{tabular}{|l|c|c|c|}
\hline Abatement & Land & Improvement & $\begin{array}{c}\text { Tax } \\
\text { Payment* }\end{array}$ \\
\hline No Abatement & 66.61 & $66.61^{* *}$ & $\$ 1,998$ \\
NEZN & 66.61 & 15.24 & $\$ 971$ \\
NEZH & 66.61 & 53.82 & $\$ 1,743$ \\
RZ & 21.91 & 21.91 & $\$ 657$ \\
\hline
\end{tabular}

*The tax payment reported here is for a property with land value equal to $\$ 20,000$ and improvement value of $\$ 40,000$.

**This rate is multiplied by the pre-rehabilitated taxable value of qualified properties

$<$ Figure 2 about here $>$

\footnotetext{
${ }^{13}$ For more detail concerning the neighborhood enterprise zones, see: 1) http://www.michiganadvantage.org/cm/Files/Fact-Sheets/NeighborhoodEnterpriseZone.pdf and 2) http://www.michigan.gov/documents/taxes/NEZ FAQ 276616 7.pdf

${ }_{14}$ This appendix was removed to reduce the size of the document, and is available upon request from the authors.

15 Due to the nature of the tax payment reduction associated with the NEZR program and the taxable value cap (a freeze or reduction in qualifying property taxable value), we are not able to calculate the tax payment for these abatements. Later, we use regression analysis to estimate the effects of these programs.

16 This figure was removed to reduce the size of the document, and is available upon request from the authors.
} 
While components of the analysis presented in this paper include an evaluation of the distributional implications of these tax abatement programs, the focus is primarily on evaluating the assessment growth limit because it affects all property owners and is one of the largest tax expenditures. ${ }^{17}$ In this context, we now turn to a review of the most relevant literature on assessment growth limits.

\section{LITERATURE ON PROPERTY TAX LIMITATIONS}

Early empirical research on property tax limits, including assessment growth limits, focused on the degree to which these fiscal institutions constrained growth of government (Dye, McGuire, \& McMillen, 2005; Mullins \& Joyce, 1996; Skidmore, 1999). More recently, researchers have focused their attention on property tax payment inequity introduced by assessment growth limits, and we focus on this research here.

Dye, McMillen, \& Merriman (2006) consider the assessment growth cap introduced in Cook County, Illinois, in 2004. They demonstrate that in order to maintain property tax revenues after introducing a taxable value cap for residential property (as in Cook County), taxes will necessarily increase for properties receiving little to no benefit, unless there is an increase in some other source of revenue. Focusing on the potential increase taxes for non-beneficiaries, the researchers discuss the implications for two groups: 1) industrial and commercial property owners, and 2) homeowners with taxable values that appreciate at a rate lower than the specified cap. Dye, McMillen, and Merriman (2006) conclude that imposing an assessment growth cap on residential properties creates inequity between residential and industrial property classes as well as among properties within the residential class. Validating the proposition that a taxable value

\footnotetext{
${ }^{17}$ In future research, we plan to more carefully consider the implications of these other tax abatement programs.
} 
cap can result in an increase in taxes for some homeowners, the Minnesota Department of Revenue (2007) reported that in 200684 percent of residential homesteads in Minnesota paid a higher tax than they would have had taxable values remained unrestricted, all else equal.

Muhammad (2007) evaluated inequities resulting from the District of Columbia's taxable value cap policy, which was imposed in 2002. Using taxable values and estimated market values for all homes in the District of Columbia, Muhammad uncovered significant horizontal inequity; he shows that effective tax rates for homesteads worth $\$ 600,000$ are as high as $\$ 0.79$ and as low as $\$ 0.01$. Further highlighting extreme vertical inequity, Muhammad identifies 24 homestead properties valued at more than $\$ 2$ million, but had tax liabilities equal to or less than that of nontax capped homestead properties valued at just $\$ 100,000$.

Skidmore, Ballard, \& Hodge (2010) examined statewide distributional effects on property tax payments resulting from of Michigan's taxable value cap using data collected from the 2008 State of the State Survey. They find long-time homeowners enjoyed an average reduction in their effective tax rates equal to about 19 percent. They also present evidence that older homeowners and those with higher incomes benefitted most from reduced effective tax rates resulting from the taxable value cap. ${ }^{18}$

\section{METHODS}

\subsection{Effective Tax Rates}

Differences in effective tax rates may emerge from both property value assessment practices and property tax policies. As shown in McMillen (2010), assessment practices can lead to substantial inequities and can increase the regressivity of the property tax. While the degree to

\footnotetext{
${ }^{18}$ For other work examining the on the consequences of property value assessment growth limits, see Bowman (2006), Giertz (2006), Anderson \& McGuire (2007), Youngman (2007), Mikesell \& Mullins (2008), and Skidmore \& Tosun (2011).
} 
which assessment practices effect property tax burdens is an important question, our focus in this paper is on the degree to which the taxable value cap leads to inequities. In order to disentangle the effects of the taxable value cap from the potential distortions caused by assessment practices, for purposes of this study we assume that state equalized value generally reflect actual market values.

Absent the assessment growth limit and property tax abatement programs, property tax payments for each parcel in Michigan would equal the property's state equalized value multiplied by the statutory rate (66.61 mills). However, with the assessment growth cap and property tax abatements, the property tax payment is equal to the property's taxable value multiplied by the millage rate that applies to the property. As previously highlighted, a property's TV differs from its SEV as a result of the assessment growth limit and the millage rate each property is subject to differs depending on abatements received. The effective tax rate is therefore a more accurate measure of tax burden than is the statutory tax rate. In this context, the effective tax rate for residential property $i\left(E F F E C T I V E R A T E_{i}\right)$ is given by the following equation:

[1] EFFECTIVE RATE $E_{i}=\left[\left(T P_{i}\right) /\left(S E V_{i}\right)\right]=\mathrm{f}\left[T_{i}, r, V_{i}, C_{i}, L_{i}\right]$

Equation (1) shows that the effective rate for homestead $i$ depends on the tax payment $\left(T P_{i}\right)$ and the state equalized value $\left(S E V_{i}\right)$, where SEV reflects the actual market or full value of the property. Upon cursory examination, it may seem that determining the cause of effective tax rate differentials requires a relatively straightforward calculation. The tax payment depends on the statutory millage and the taxable value of a property. If one knows the date of last sale, it is possible to determine the annual growth in taxable value, which is specified to grow at the rate of inflation. However, determining growth in SEV for a specific property is more problematic; 
SEV growth differs from year to year and across space, and information on these patterns across the city is unavailable. We therefore use econometric methods to examine the underlying determinants of effective tax rate differentials.

Although all properties in Detroit face the same statutory rate, depending on which abatement programs for which the property qualifies and the degree to which the property is protected by the taxable value cap, effective tax rate differs considerably from property to property. In this context the effective tax rate depends on the length of time an individual has owned the property $\left(T_{i}\right)$, the rate of inflation multiplier $(r)$, the appreciation (or depreciation) of property value $\left(V_{i}\right)$, the characteristics of the property $\left(C_{i}\right),{ }^{19}$ and the location of the property $\left(L_{i}\right) .{ }^{20}$ These factors illustrate the ways in which differences in effective tax rates can emerge. The less a property owner benefits from the taxable value cap and various tax abatement programs, the closer the effective rate will be to the statutory rate.

Figures 3 and 4 illustrate the variation in effective tax rates across Detroit. Figure 3 presents average effective tax rates of owner-occupied residential properties at the neighborhood level, and Figure 4 shows the variation of effective tax rates between all taxable properties within a single illustrative Detroit neighborhood. ${ }^{21}$ Together, these maps highlight the substantial variation in effective rates across neighborhoods and between neighbors within a given neighborhood.

\footnotetext{
${ }^{19}$ Characteristics such as age of the house, lot size, house size, etc. are important determinants of the sales price (related to SEV and TV).

${ }^{20}$ The location of the property determines whether or not a property owner may benefit from any of the targeted abatement programs. Also, location may influence the growth in state equalized value since properties in more desirable locations may experience larger growth in market values relative to properties in less desirable neighborhoods.

${ }^{21}$ In Figure 3, crosshatched neighborhoods represent those that do not have any owner-occupied residential properties. Crosshatched parcels in Figure 4 represent nontaxable properties. Figure 4 includes all taxable properties to highlight the wide variation in effective tax rates between neighbors, including non-homestead properties.
} 
Figure 3: Average Effective Tax Rates of Owner-Occupied Residential Properties by Detroit Neighborhood, 2010

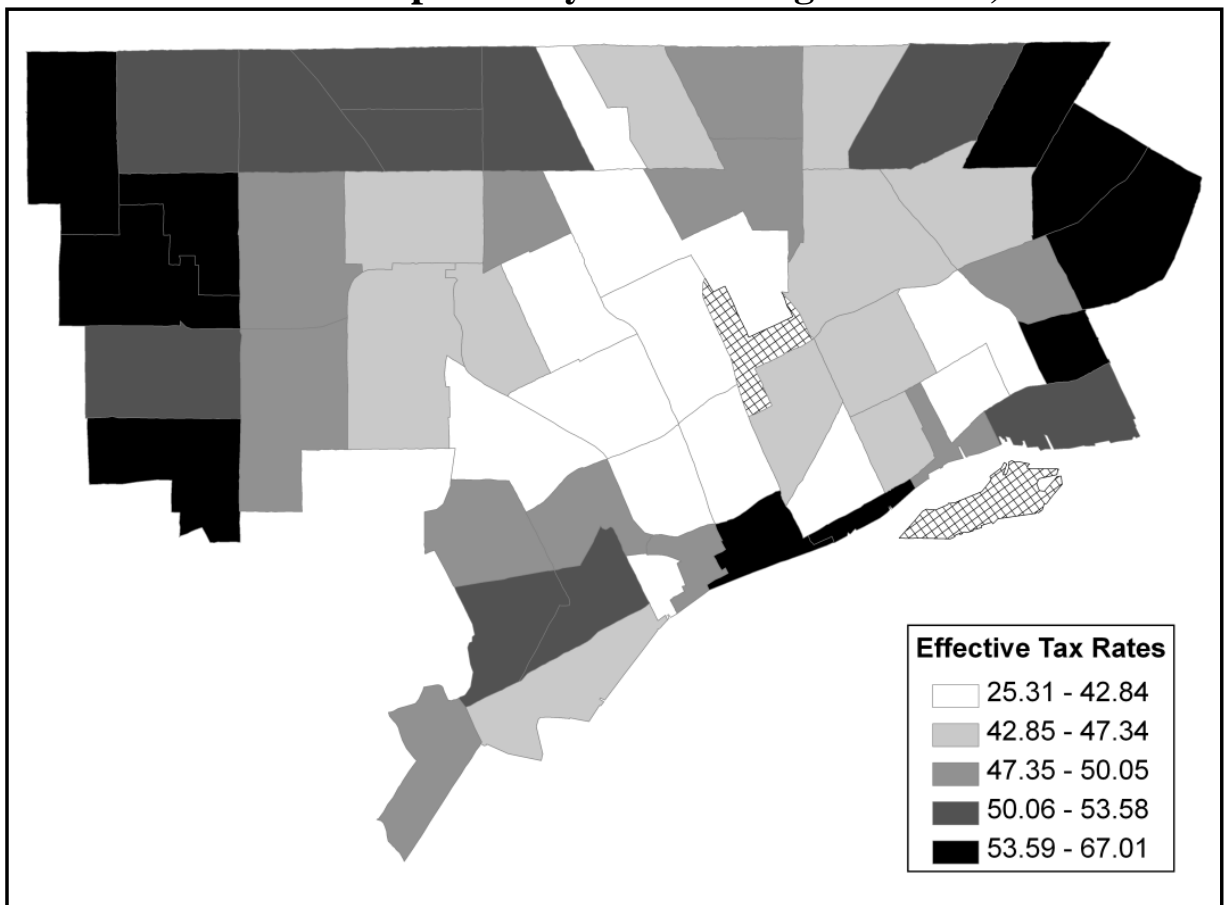

Source: Neighborhood shapefiles and tax data to calculate effective tax rates provided by the City of Detroit Assessment Division. 
Figure 4: Parcel Level Effective Tax Rates between All Taxable Properties, 2010

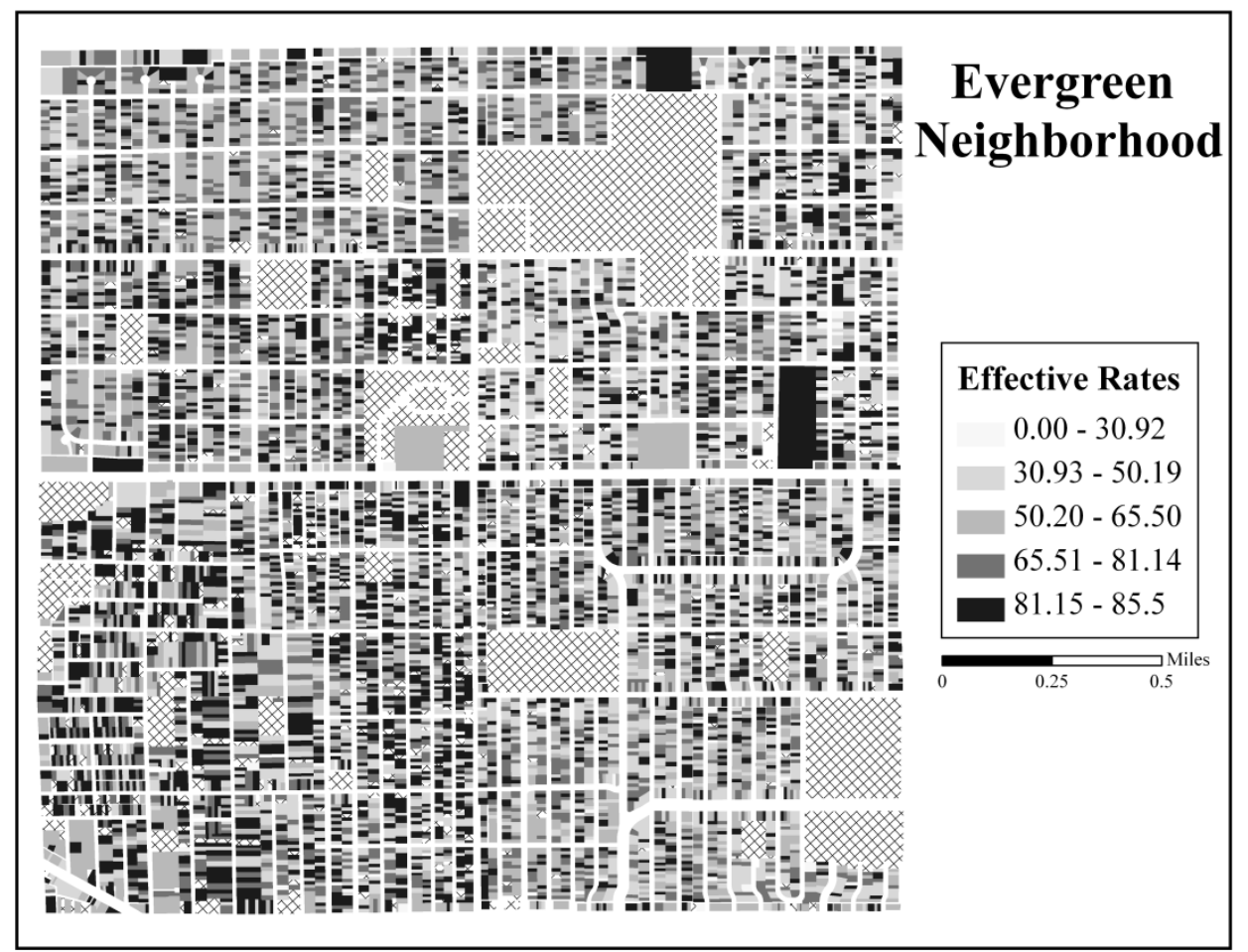

Source: Parcel level shapefiles and tax data provided by the City of Detroit Assessment Division.

\subsection{Model}

One strategy for estimating the effect of the assessment growth limit on effective tax rates is to use ordinary least squares regression analysis. This approach is represented by equation [2]:

$$
\text { EFFECTIVE RATE } E_{i}=C_{i} \tau+\alpha N E Z R_{i}+\beta N E Z N_{i}+\gamma N E Z H_{i}+\eta R Z_{i}+\delta T_{i}+\theta L_{i}+\varepsilon_{i}
$$

where EFFECTIVE RATE $E_{i}$ is the effective property tax rate, $C_{i}$ is a vector of property characteristics, $N E Z R_{i}$ through $N E Z H_{i}$ are indicator variables representing whether or not property $i$ is benefitting from each portion of the Neighborhood Enterprise Zone program, $R Z_{i}$ is an indicator variable representing residential properties located within a Renaissance Zone, $T_{i}$ is the length of time that homeowner $i$ has owned his or her property since the imposition of the assessment growth cap (Years of Ownership), $L_{i}$ indicates in which neighborhood property $i$ is located, and $\varepsilon_{\mathrm{i}}$ is the error term. Of primary interest is $T_{i}$; generally we expect that the longer a 
homeowner retains ownership, the lower the effective tax rate will be.

\subsection{Examining Effects on the Full Distribution: Quantile Regression Analysis}

While measuring the effect of policies "on average" provides a good initial assessment, observing the mean effect yields a limited perspective of how policy changes affect the location of and shape of distributions (Buchinsky, 1994). To determine how the conditional distribution of effective tax rates varies given the covariates, we use a quantile regression model $(\mathrm{QRM}){ }^{22}$ In the context of effective tax rates, the quantile regression approach provides a more complete evaluation of horizontal and vertical equity because it shows whether the assessment growth limit creates more or less variable effective tax rates within and across property value groups. One could potentially use standard regression techniques to examine central tendencies across points within the full distribution of effective tax rates; however, one would need to identify and use an appropriate functional form. However, as our QRM results demonstrate, identifying an appropriate specification can be a difficult task given that there is no a priori knowledge on how the taxable value cap is expected to alter the distribution of effective tax rates.

Predictions from quantile regressions enables one to examine changes in the distribution of the dependent variable because QRM allows the distribution of the dependent variable to differ from the covariate's underlying density - since the coefficients differ across quantiles. As an illustration of the difference between the quantile regression and the linear regression approaches, consider an example taken from McMillen (2012). Equation [3.1] provides the standard linear regression equation:

\section{[3.1] $E(y \mid X)=\beta_{0}+\beta_{1} x_{1}+\ldots+\beta_{i} x_{i}+u$}

\footnotetext{
${ }^{22}$ Koenker and Bassett (1978) first introduced the quantile regression model.
} 
Where $y$ is the dependent variable, $x_{i}$ is independent variable $i$, and $\beta$ is the coefficient. To see the effect on the distribution of $y$ by changing the value of the covariate $x_{1}$ from $\delta_{0}$ to $\delta_{1}$, consider equations [3.2] and [3.3]:

$$
E\left(y \mid X, x_{1}=\delta_{0}\right)=\hat{\beta}_{0}+\hat{\beta}_{1} \delta_{0}+\ldots+\hat{\beta}_{i} x_{i}
$$

$$
E\left(y \mid X, x_{1}=\delta_{1}\right)=\hat{\beta}_{0}+\hat{\beta}_{1} \delta_{1}+\ldots+\hat{\beta}_{i} x_{i}
$$

The distribution will shift right by $\hat{\beta}_{1}\left(\delta_{1}-\delta_{0}\right)$ if $\hat{\beta}_{1}>0$ and will shift left by $\left|\hat{\beta}_{1}\left(\delta_{1}-\delta_{0}\right)\right|$ if $\hat{\beta}_{1}<0$ while retaining the assumed shape of the distribution. This is known as a location shift (Hao and Naiman, 2007). While it may be reasonable to expect a parallel shift in the distribution of $y$ in many contexts, it is a limitation we do not want to impose if we are interested in understanding how the distribution of $y$ may change with respect to changes in the covariates.

To better understand how QRM enables one to estimate changes in the distribution of $y$ as the covariates change (i.e. allows both a location and scale shift), consider a quantile regression model similar to that of Hao and Naiman (2007) where the $p$ th conditional quantile specified as follows:

$$
Q^{(p)}(y \mid X)=\beta_{0}^{(p)}+\beta_{1}^{(p)} x_{1}+\ldots+\beta_{i}^{(p)} x_{i}+u^{(p)} \quad, \quad 0<p<1
$$

Here, the $p$ th conditional quantile is determined by the quantile specific parameters, $\beta_{0}^{(p)}$ through $\beta_{i}^{(p)}$, and the values of each covariate. This approach allows one to trace out the entire conditional distribution of $y$ as the quantiles are increased continuously from 0 to 1 (Buchinsky, 1998). The effect of covariates on the distribution of $y$ across quantiles is illustrated by equations [4.2] and [4.3]:

$$
Q^{(p)}\left(y \mid X, x_{1}=\delta_{0}\right)=\hat{\beta}_{0}^{(p)}+\hat{\beta}_{1}^{(p)} \delta_{0}+\ldots+\hat{\beta}_{i}^{(p)} x_{i} \quad, \quad 0<p<1
$$




$$
Q^{(p)}\left(y \mid X, x_{1}=\delta_{1}\right)=\hat{\beta}_{0}^{(p)}+\hat{\beta}_{1}^{(p)} \delta_{1}+\ldots+\hat{\beta}_{i}^{(p)} x_{i} \quad, \quad 0<p<1
$$

Since $\hat{\beta}_{1}^{(p)}$ varies across quantiles, the conditional quantile functions imply a full distribution of values for $y$. Restated, changes in $x_{1}$ can result in both a scale $\operatorname{shift}\left(\hat{\beta}_{1}^{(p)}\right.$ differs across each quantile) and a relocation of the conditional distribution of $y$. In order to estimate a similar effect using standard regression analysis, one would need to make assumptions about the distribution and correctly specify the functional form. In the context of the present study, this is a difficult task because there is no clear theoretical basis for predicting how the assessment growth limit might alter the distribution of effective tax rates across property value groups. In addition to the advantages outlined above, Buchinsky (1998) also shows that relative to standard ordinary least squares analysis, QRM is more robust to outliers and more efficient when the error term is non-normal.

Equations 4.2 and 4.3 allow us to present a series of graphs showing the effects of discrete changes in an explanatory variable on the full distribution of values for y. To do so, we estimate quantile regressions for $\mathrm{p}=[0.02,0.03, \ldots, 0.98]$. Equations 4.2 and 4.3 each imply $97 \mathrm{n}$ predicted values - one for each $i=1, \ldots, n$ at each of 97 values of $p$. Kernel density estimates of the full set of predicted values for $x_{1}=\delta_{0}$ show the full distribution of values of $y$ conditional on $x_{1}=\delta_{0}$, but unconditional with respect to the other variables. Kernel density functions can then be estimated for any other target value of $x_{1}$ to show how changes in this variable affect the overall distribution of $\mathrm{y}$.

By using quantile regression techniques, the analysis presented in this paper offers a clear evaluation of: 1) how the assessment growth cap changes the distribution of effective tax rates across owner-occupied properties; 2) how the assessment growth cap alters effective tax rate 
distributions within property value groups (i.e. horizontal inequity); and 3) how the assessment growth cap changes the effective tax rate distributions across groups (i.e. vertical inequity).

\section{DATA}

The City of Detroit's Assessment Division provided parcel-level information for this research. Relevant information provided for each parcel in the City includes: property class, taxable status, improvements, tax payment (by taxing authority), SEV, TV, last sale date, and last sale price. Properties located in Neighborhood Enterprise Zones and Renaissance Zones were also identified.

The data include information for 444,183 real and personal property parcels, of which we focus on residential owner-occupied properties. We therefore exclude 72,864 non-residential (commercial, industrial, and/or personal), 59,402 nontaxable, 62,504 unimproved, 14,486 properties for which key information is missing (e.g. property characteristics, property class, sale date, etc.), and 124,857 non-owner occupied residential (rental or vacant housing units) parcels.

Given that our focus is on the equity implications for homeowners, the exclusion of nonresidential, unimproved, and nontaxable properties is appropriate. However, the exclusion of the 14,486 properties for which there is missing information could generate selection bias. ${ }^{23}$ These properties represent less than 15 percent of the total number of residential properties, and so it seems that any potential bias is minimal.

We must also exclude the 3,534 residential owner-occupied properties sold in $2010 .^{24}$ For these properties, the number of years of ownership is updated upon sale to reflect the new

\footnotetext{
${ }^{23}$ Of these properties, nearly 10,000 of them are NEZ properties that do not include the required information. Multiple formal requests for this information have been made with the City of Detroit's Assessment Division.

${ }^{24}$ Including these observations does not change the results presented below.
} 
ownership, but any changes in TV are not reflected in the assessment rolls until the following year. Thus, TV in the first year of ownership reflects the previous owner's TV and not that of the new owner.

In total, there are 106,536 owner-occupied properties for which we have all of the needed information to include in the analysis. Summary statistics for the variables used in the analysis are presented in Table 3 and detailed definitions for these variables are provided in Appendix $2^{25}$. Table 3 includes summary statistics for the full sample, as well as for ten sub-groups based on the size of SEV.

25 This appendix was removed to reduce the size of the document, and is available upon request from the authors. 
Table 3: Summary Statistics

\begin{tabular}{|c|c|c|c|c|c|c|c|c|}
\hline \multirow[b]{2}{*}{ Variable } & \multicolumn{2}{|c|}{ Full Sample } & \multicolumn{2}{|c|}{ SEV Decile 1} & \multicolumn{2}{|c|}{ SEV Decile 2} & \multicolumn{2}{|c|}{ SEV Decile 3} \\
\hline & Mean & Std Dev. & Mean & Std Dev. & Mean & Std Dev. & Mean & Std Dev. \\
\hline Effective Tax Rate & 49.65 & 14.43 & 56.39 & 13.91 & 47.32 & 16.23 & 46.10 & 16.23 \\
\hline$S E V$ & 28,629 & 14,710 & 7,244 & 2,724 & 14,470 & 1,596 & 19,193 & 1,232 \\
\hline Living Area & 1,161 & 1,259 & 1,077 & 432.6 & 1,048 & 352.8 & 1,022 & 340.6 \\
\hline Lot Size & 874.8 & 1,063 & 776.1 & 248.3 & 763.6 & 174.5 & 777.6 & 153.7 \\
\hline Age & 6.703 & 1.502 & 8.256 & 1.453 & 7.773 & 1.524 & 7.200 & 1.471 \\
\hline Condo & 0.003 & 0.051 & 0.008 & 0.091 & 0.002 & 0.042 & 0.000 & 0.022 \\
\hline$N E Z-R$ & 0.00003 & 0.005 & - & - & - & - & - & - \\
\hline$N E Z-N$ & 0.001 & 0.031 & 0.0001 & 0.010 & - & - & - & - \\
\hline$N E Z-H$ & 0.002 & 0.047 & - & - & 0.0001 & 0.010 & - & - \\
\hline$R Z$ & 0.001 & 0.031 & 0.006 & 0.079 & 0.001 & 0.028 & 0.001 & 0.035 \\
\hline Years of Ownership & 13.08 & 4.672 & 13.75 & 4.229 & 13.01 & 4.663 & 12.80 & 4.788 \\
\hline \# of Obs. & \multicolumn{2}{|c|}{103,027} & \multicolumn{2}{|c|}{10,461} & \multicolumn{2}{|c|}{10,379} & \multicolumn{2}{|c|}{10,327} \\
\hline
\end{tabular}

\begin{tabular}{|c|c|c|c|c|c|c|c|c|}
\hline \multirow[b]{2}{*}{ Effective Tax Rate } & \multicolumn{2}{|c|}{ SEV Decile 4} & \multicolumn{2}{|c|}{ SEV Decile 5} & \multicolumn{2}{|c|}{ SEV Decile 6} & \multicolumn{2}{|c|}{ SEV Decile 7} \\
\hline & 47.28 & 15.59 & 48.40 & 14.92 & 48.99 & 14.25 & 50.51 & 13.22 \\
\hline$S E V$ & 23,170 & 1,046 & 26,529 & 928.4 & 29,680 & 892.4 & 32,756 & 891.3 \\
\hline Living Area & 980.1 & 326.0 & 992.0 & 498.3 & 1,022 & 611.5 & 1,050 & 436.5 \\
\hline Lot Size & 800.2 & 151.3 & 820.1 & 326.1 & 845.9 & 556.6 & 853.4 & 317.6 \\
\hline Age & 6.601 & 1.376 & 6.358 & 1.212 & 6.267 & 1.119 & 6.163 & 1.082 \\
\hline Condo & 0.001 & 0.024 & 0.0005 & 0.022 & 0.001 & 0.024 & 0.0004 & 0.020 \\
\hline$N E Z-R$ & - & - & - & - & 0.0001 & 0.010 & - & - \\
\hline$N E Z-N$ & 0.0001 & 0.010 & 0.0001 & 0.010 & - & - & 0.0002 & 0.014 \\
\hline$N E Z-H$ & 0.001 & 0.028 & 0.001 & 0.026 & 0.001 & 0.038 & 0.002 & 0.043 \\
\hline$R Z$ & 0.0003 & 0.017 & 0.0001 & 0.010 & 0.0001 & 0.010 & 0.0005 & 0.022 \\
\hline Years of Ownership & 12.78 & 4.737 & 12.77 & 4.746 & 12.86 & 4.738 & 12.87 & 4.739 \\
\hline \# of Obs. & \multicolumn{2}{|c|}{10,294} & \multicolumn{2}{|c|}{10,272} & \multicolumn{2}{|c|}{10,260} & \multicolumn{2}{|c|}{10,272} \\
\hline
\end{tabular}


Table 3: (cont'd)

\begin{tabular}{|c|c|c|c|c|c|c|}
\hline \multirow[b]{2}{*}{ Variable } & \multicolumn{2}{|c|}{ SEV Decile 8} & \multicolumn{2}{|c|}{ SEV Decile 9} & \multicolumn{2}{|c|}{ SEV Decile 10} \\
\hline & Mean & Std Dev. & Mean & Std Dev. & Mean & Std Dev. \\
\hline Effective Tax Rate & 50.66 & 12.57 & 50.04 & 12.19 & 50.74 & 11.64 \\
\hline$S E V$ & 36,163 & 1,111 & 41,101 & 1,882 & 56,650 & 18,546 \\
\hline Living Area & 1,121 & 823.1 & 1,258 & 701.5 & 2,047 & 3,530 \\
\hline Lot Size & 881.2 & 744.3 & 896.1 & 551.4 & 1,338 & 3,094 \\
\hline Age & 6.052 & 1.074 & 6.037 & 1.215 & 6.282 & 1.426 \\
\hline Condo & 0.001 & 0.037 & 0.004 & 0.065 & 0.008 & 0.089 \\
\hline$N E Z-R$ & - & - & - & - & 0.0002 & 0.014 \\
\hline$N E Z-N$ & 0.001 & 0.030 & 0.004 & 0.061 & 0.005 & 0.068 \\
\hline$N E Z-H$ & 0.002 & 0.047 & 0.003 & 0.058 & 0.012 & 0.109 \\
\hline$R Z$ & 0.0001 & 0.010 & 0.0001 & 0.010 & - & - \\
\hline Years of Ownership & 13.03 & 4.692 & 13.22 & 4.706 & 13.68 & 4.541 \\
\hline$\#$ of Obs. & \multicolumn{2}{|c|}{10,239} & \multicolumn{2}{|c|}{10,261} & \multicolumn{2}{|c|}{10,262} \\
\hline
\end{tabular}

From Table 3, the average effective property tax rate is 49.65 mills, but there are differences across the sub-samples. Property owners with the lowest valued properties have an average effective tax rate that is much higher than the remaining groups, even though the average number of years the properties are owned is similar across all groups. The relatively high effective tax rates for low valued properties may be the result of this group losing the most value in the wake of the recent housing market crisis. ${ }^{26}$ In the full sample, as with each property value group, it is not surprising to see that the average effective tax rate is less than the average statutory tax rate. This differential is the result of the erosion of the property tax base from the taxable value cap, as well as the reduced rates in the Renaissance Zone and Neighborhood Enterprise Zone programs.

It is important to note that in our data there are few properties that qualify for each portion of the NEZ program: about 200 properties qualify for the NEZH program; 100 qualify

\footnotetext{
${ }^{26}$ This observation reflects the recent downturn because the average taxable value of the group will converge to state equalized value (holding other factors constant) if the value of these properties has been stable or lost value.
} 
for the NEZN program; three qualify for the NEZR program; and 100 residential properties are within Renaissance Zones. ${ }^{27}$ Also, the number of owner-occupied properties qualifying for these programs across SEV sub-groups varies greatly, with many of the groups having zero properties benefitting from the zones.

\section{RESULTS}

\subsection{Traditional Analysis: Measuring the Average Effect}

Following a more traditional approach of measuring the effect of an assessment growth cap on effective tax rates, this analysis begins with a standard ordinary least squares regression analysis to measure the mean effect across all owner-occupied residential properties as reported in Table 4: column (1) reports the average effect of the assessment growth cap across all properties. We also present the ordinary least squares analysis in order to more clearly show how quantile regression analysis (or main contribution) offers a more complete and much richer evaluation. To examine the average effects across different property value groups, in column (2) we report an interaction term between the Years of Ownership and SEV. The Years of Ownership $\times S E V$ interaction term provides an initial evaluation of the vertical inequity stemming from the assessment growth cap.

\footnotetext{
${ }^{27}$ The number of properties qualifying for the NEZ program in our sample is low compared to the actual total number of qualifying NEZ properties. A large number of NEZ properties are not included because they are missing important information. Specifically, the data provided by the City of Detroit does not include the following (for most NEZ properties): floor area, year built, last sale date, and last sale amount. A formal request for this information has been made with the City of Detroit's Assessment Division.
} 
Table 4: OLS Effective Tax Rate Regression Results

\begin{tabular}{|lcc|}
\hline \multirow{2}{*}{ Independent Variable } & \multicolumn{2}{c|}{ OLS } \\
\cline { 2 - 3 } Constant & $77.449^{* * *}$ & $(\mathbf{2})$ \\
& $(0.661)$ & $85.848^{* * *}$ \\
Living Area & $-0.0005^{* * *}$ & $(0.677)$ \\
& $(0.0001)$ & $0.003^{* * *}$ \\
Lot Size & $0.0007^{* * *}$ & $(0.0002)$ \\
& $(0.0001)$ & $-0.002^{* * *}$ \\
Age & $-0.751^{* * *}$ & $(0.0002)$ \\
& $(0.040)$ & $-1.401^{* * *}$ \\
Condo & $15.232^{* * *}$ & $(0.043)$ \\
& $(1.062)$ & $13.522^{* * *}$ \\
NEZR & $-33.223^{* * *}$ & $(1.094)$ \\
& $(8.430)$ & $-27.256^{* *}$ \\
NEZN & $-15.060^{* * *}$ & $(11.635)$ \\
& $(2.133)$ & $-12.715^{* * *}$ \\
NEZH & $-12.498^{* * *}$ & $(2.089)$ \\
& $(0.493)$ & $-10.246^{* * *}$ \\
RZ & 0.877 & $(0.527)$ \\
& $(2.053)$ & 0.531 \\
Years of Ownership & $-1.771^{* * *}$ & $(1.947)$ \\
& $(0.007)$ & $-1.870^{* * *}$ \\
SEV & - & $(0.019)$ \\
Years of Ownership & & $-0.0003^{* * *}$ \\
x SEV & - & $(0.00001)$ \\
Nhood Fixed Effects & & $0.000004^{* * *}$ \\
\# of Obs. & & $(0.000001)$ \\
\hline R-squared & 0.414 & \\
\hline
\end{tabular}

Notes: Standard errors are in parentheses. All regressions include all control variables and are corrected for heteroskedasticity. Asterisks denote significance at the $1 \%(* * *), 5 \%(* *)$, and $10 \%(*)$ levels.

Consider first the results of the property characteristics. The coefficient for Age is negative and statistically significant: all else equal, older properties have lower effective tax rates. The coefficient for Condo is positive and statistically significant, indicating that condominiums have higher effective tax rates. In column 1, the coefficients on living area and lot size are negative and positive, respectively. However, once we control for SEV as in column 2 the signs are reversed. Once we control for SEV, we see that larger homes on smaller lots tend 
to have lower effective tax rates. We present both regressions because SEV is the denominator in the effective tax rate definition, and so it arguably endogenous and should not be included in the regression. However, note that the coefficient on Years of Ownership, our primary interest, is similar in both regressions.

Next, consider the effects of abatement zones on effective tax rates. As expected, properties qualifying for each type of Neighborhood Enterprise Zone receive large reductions in effective tax rates. NEZ Homestead properties receive an average reduction of 10 to 12.5 mills. This estimate is nearly identical to the full benefit of qualified properties as previously discussed. Properties qualifying for NEZN benefits receive an average reduction of 12.5 to 15 mills, lower than one might expect given that these properties are eligible for a reduced millage rate equal to 15.24 mills for the improved portion of property, with the land portion of the tax being taxed at the full rate. However, given that there is a three-year phase in to full taxation for expiring zones and most NEZN properties are in zones that are nearing expiration, the average measured tax reduction is less generous than anticipated. Perhaps the most interesting finding among the NEZ programs is the effect from the rehab portion (NEZR). ${ }^{28}$ Recall that it is difficult to know precisely how large NEZR benefits are because the improved portion of property is frozen at the pre-rehab taxable value. The estimates in Table 4 show an average reduction in effective tax rates of 27 to 33 mills, a saving of 41 to 50 as compared with non-NEZR properties receiving no other benefits. Finally, properties located within a Renaissance Zone experience no change in their effective tax rate as the coefficient is statistically insignificant.

Consider now the effect of Years of Ownership on effective tax rates. All else equal, effective property tax rates are significantly reduced as the number of ownership years increases.

\footnotetext{
${ }^{28}$ Recall that in our data we only have a few properties that qualify for and receive the NEZR abatement. We are therefore cautious in drawing strong conclusions from this estimate.
} 
Specifically, the estimates in column (1) of Table 4 show an average reduction in effective tax rates of 1.77 mills for each year of ownership, all else equal. Thus, homeowners who have lived in their home since 1994 (or earlier) face an effective property tax rate that is on average 28 mills (or 42 percent less) than effective rates faced by new homebuyers.

To examine vertical inequity stemming from the assessment growth cap, consider the results in column 2 of Table 4. Here, the coefficient on the interaction between Years of Ownership and SEV provides an initial evaluation of the effective rate reduction resulting from the taxable value cap for different property value groups. The estimates in column (2) show that the average effective tax rate decreases as years of ownership increase, but the effect diminishes as property values increase. Specifically, homeowners receive a 1.87 mill reduction in the effective tax rate for each additional year of ownership, but this reduction decreases by 0.04 mills for each $\$ 10,000$ increase in property value. According to these estimates, properties in the lowest SEV decile receive an average reduction in their effective tax rate of 1.84 mills for each additional year of ownership (approximately 29.4 mills, or a 44 percent, reduction for those retaining ownership since 1994), whereas properties in the highest SEV decile receive an average reduction of 1.64 mills for each additional year of ownership (approximately 26.2 mills, or a 39 percent reduction for those retaining ownership since 1994). This provides evidence of a modest increase in the progressivity of effective tax rates as a result of the assessment growth cap. As we show next, this result is misleading.

To further examine how the effect of the assessment growth cap is distributed across property values, we interact the length of home ownership with ten indicator variables representing SEV deciles. As presented in Table $5^{29}$, these estimates show that properties in the middle deciles tend to receive much larger effective tax rate reductions as a result of assessment

${ }^{29}$ This table was removed to reduce the size of the document, and is available upon request from the authors. 
growth cap, as much as two to three times more than the lowest valued properties. For example, homeowners in the third SEV decile (properties with an SEV equal to roughly $\$ 19,000$ ) are subject to effective tax rates that are approximately 35 mills lower (or 52 percent less) than new homebuyers with similarly valued properties. For the lowest decile, the average reduction is just 12.7 mills, and for the highest decile the average reduction is 26.2

<Table 5 about here>

To provide a clearer summary of the Table 5 estimates, Table $6^{30}$ provides estimated average tax payments for each SEV decile. The column labeled "No Tax Benefit" is the average tax payment of properties that receive no effective tax rate reduction as a result of the taxable value cap (sold in 2009) and the "Full Tax Benefit" column is the average tax payment of properties receiving the maximum effective tax rate reduction (properties last sold in 1994 or earlier). Finally, "Full Tax Benefit/No Tax Benefit" shows the ratio of taxes paid by those receiving full benefit to those receiving no benefits. As Table 6 highlights, actual tax payments vary significantly for otherwise identical properties (i.e. horizontal inequity). Specifically, a homeowner may receive a tax bill that is 19 to 52 percent higher than a neighboring homeowner with a property of similar value. Table 6 also illustrates vertical inequity. Properties enjoying full benefits of the taxable value cap in the first five deciles pay less than $\$ 900$ in taxes. Those properties receiving no benefits reach this tax level in the second decile. Thus, a home valued at $\$ 26,500$ (decile 5) with full tax benefits pays as little as $\$ 894$, whereas, without benefits a property valued at $\$ 14,500$ owes as much as $\$ 967$.

30 This table was removed to reduce the size of the document, and is available upon request from the authors. 
<Table 6 about here>

\subsection{Quantile Regression Analysis: Examining the Full Distributional Effect}

We now turn to the quantile regression approach, which offers additional insight on how the assessment growth cap altered effective tax rate distributions. The standard quantile regression estimates are presented in Table 7, and the quantile regression coefficients for quantiles ranging from $p=0.01,0.02, \ldots, 0.99$ are presented in Appendix $3^{31}$. Mirroring the OLS results, the estimates imply that effective tax rates are higher for more recently sold properties, non-NEZ properties, and properties with newer houses. Focusing more specifically on the coefficients for Years of Ownership across quantiles, the slope is much steeper at the $10 \%$ quantile than at the $90 \%$ quantiles - indicating that effective tax rates are diverging as the years of ownership increases (i.e. the distribution's variance increases with length of tenure). In fact, most of the policy variables appear to increase the variance of the effective tax rate.

Table 7: Effective Tax Rate Quantile Regression Results

\begin{tabular}{|lccc|c|}
\hline & \multicolumn{4}{c|}{ Quantile } \\
\cline { 2 - 5 } Independent Variable & $\mathbf{1 0 \%}$ & $\mathbf{5 0 \%}$ & $\mathbf{9 0 \%}$ & $\mathbf{9 0 \%}-\mathbf{1 0 \%}$ \\
Constant & $57.351^{* * *}$ & $80.670^{* * *}$ & $66.727 * * *$ & $9.376^{* * *}$ \\
& $(0.617)$ & $(0.496)$ & $(0.490)$ & $(0.814)$ \\
Living Area & $0.0003 *$ & -0.00003 & -0.000002 & $-0.0003 * *$ \\
& $(0.0001)$ & $(0.0001)$ & $(0.0001)$ & $(0.0001)$ \\
Lot Size & -0.00008 & 0.0002 & 0.000003 & 0.00009 \\
& $(0.0002)$ & $(0.0001)$ & $(0.0001)$ & $(0.0001)$ \\
Age & $-1.166^{* * *}$ & $-1.052 * * *$ & -0.0008 & $1.165 * * *$ \\
& $(0.046)$ & $(0.037)$ & $(0.037)$ & $(0.048)$ \\
Condo & $10.030^{* * *}$ & $19.935 * * *$ & 0.019 & $-10.011 * * *$ \\
& $(1.279)$ & $(1.027)$ & $(1.016)$ & $(1.153)$ \\
NEZR & $-26.098 * * *$ & $-46.021 * * *$ & -0.039 & 26.059 \\
& $(9.227)$ & $(7.412)$ & $(7.332)$ & $(22.862)$
\end{tabular}

31 This appendix was removed to reduce the size of the document, and is available upon request from the authors. 


\begin{tabular}{|c|c|c|c|c|}
\hline$N E Z N$ & $-25.929 * * *$ & $-15.279 * * *$ & $-8.158 * * *$ & $\begin{array}{c}17.771 * * \\
(8389)\end{array}$ \\
\hline & $-11.843 * * *$ & $-14.365 * * *$ & $-12.196 * * *$ & -0.353 \\
\hline$N E Z H$ & $(1.030)$ & $(0.827)$ & $(0.818)$ & $(0.339)$ \\
\hline & $-8.908 * * *$ & $2.955 * *$ & 0.002 & $8.910 * * *$ \\
\hline RL & (1.614) & $(1.297)$ & $(1.282)$ & $(3.278)$ \\
\hline & $-1.828 * * *$ & $-1.894 * * *$ & -0.004 & $1.824 * * *$ \\
\hline Years of Ownership & $(0.011)$ & $(0.009)$ & $(0.008)$ & $(0.014)$ \\
\hline Nhood Fixed Effects & \multicolumn{4}{|c|}{ Yes } \\
\hline \# of Obs. & \multicolumn{4}{|c|}{103,027} \\
\hline
\end{tabular}

Notes: Standard errors are in parentheses and the standard errors for the last column are from 100 bootstrap replications. Asterisks denote significance at the 1\%(***),5\%(**), and 10\% (*) levels.

To more formally examine whether or not the assessment growth cap and the abatement zones change the effective tax rate variance (i.e. scale shift), we test differences between coefficient estimates across quantiles. The difference between the $10 \%$ and $90 \%$ quantiles are presented in the last column of Table 7. For the NEZR and NEZH abatements, the difference between quantiles is statistically insignificant. That is, these policies do not change the effective tax rate variance; rather, the effective tax rate distribution shifts left. However, the difference between the $10 \%$ and $90 \%$ for properties located in Renaissance Zones (RZ), NEZNs, and those benefitting from years of ownership via the taxable value cap are statistically significant. In these cases, the effective tax rate distribution shifts left and becomes wider.

While examining the changes in effective tax rate variance is relatively straightforward, the results presented in Table 7 require some additional explanation. Interpretation of the quantile regression estimates is perhaps most easily understood with graphical illustrations of how the distribution changes as an explanatory variable takes on different values. Focusing on the effect of the assessment growth cap via Years of Ownership, Figure 5 presents a graph of the estimated conditional density functions of effective tax rates for properties sold in 1994 or earlier, sold in 2000, and sold 2008. Figure 5 provides a clear evaluation of degree of inequity 
resulting from the assessment growth cap. ${ }^{32}$ Effective tax rates are tightly clustered around the full millage rate for properties sold in 2008. However, as the years of property ownership increases the distribution shifts to the left and has a much greater variance. Also, note the bimodal distribution for properties owned since 1994. The small bump on the right represents properties sold in 1994 that no longer receive an effective tax rate reduction from the assessment growth cap. For these properties, the tax benefits have eroded as a result of property value declines caused by the housing market collapse.

Figure 5: Effect of Assessment Growth Cap on Estimated Effective Tax Rate Densities

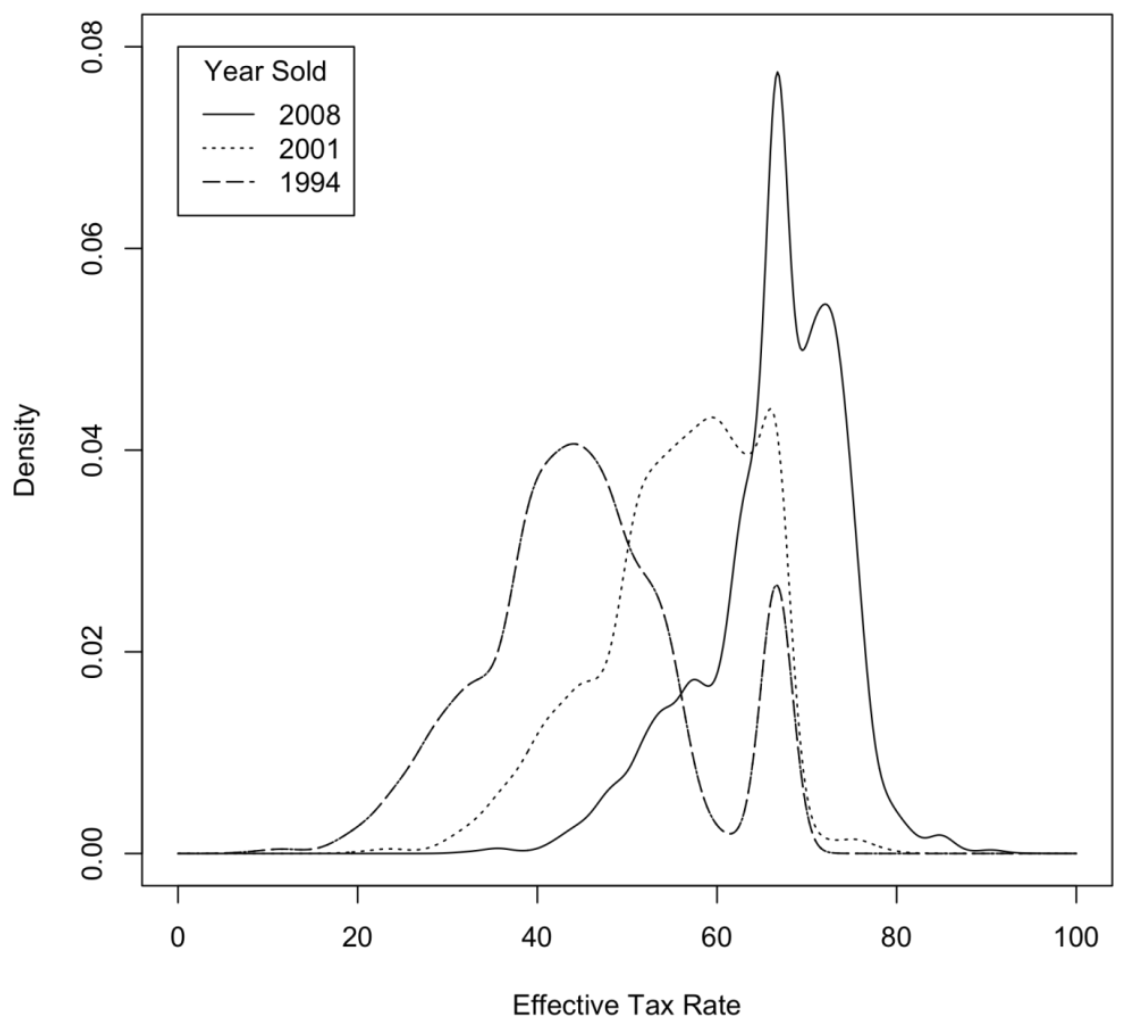

${ }^{32}$ Similar changes in effective tax rates as a result of the different NEZ programs were also examined. The resulting distribution shifts were as expected given the nature of the programs and the results from testing the difference across quantiles - the effective tax rate distribution the mean value shifted to the left, but the variance experienced little to no change. A graph highlighting this result is presented in Appendix 4, which is available from the authors upon request. 


\subsection{Quantile Regression Analysis: Horizontal Inequity}

Standard quantile regression estimates by SEV deciles are presented in Table 8 , as well as the differences between the $10 \%$ and $90 \%$ quantiles. These estimates show that effective tax rates are higher for recent purchasers of property across all SEV deciles. In contrast to the previous results, the variance of effective tax rates does not always increase as the length of tenure increases; rather, the variance increases as the length of homeownership increases only for the first two deciles. The variance does not change for deciles three to five and the variance decreases as the length of homeownership increases for the remaining groups.

Table 8: Effective Tax Rate Quantile Regression Results for Years of Ownership across Property Value Groups

\begin{tabular}{|lccc|c|}
\hline & \multicolumn{4}{c|}{ Quantile } \\
\cline { 2 - 5 } SEV Decile & $\mathbf{1 0 \%}$ & $\mathbf{5 0 \%}$ & $\mathbf{9 0 \%}$ & $\mathbf{9 0 \% - 1 0 \%}$ \\
\hline 1 & $-1.109^{* * *}$ & $-0.346^{* * *}$ & $-0.0006^{* * *}$ & $1.109^{* * *}$ \\
& $(0.048)$ & $(0.047)$ & $(0.0002)$ & $(0.069)$ \\
2 & $-1.688^{* * *}$ & $-2.139^{* * *}$ & $-1.023^{* * *}$ & $0.665^{* * *}$ \\
& $(0.043)$ & $(0.027)$ & $(0.082)$ & $(0.158)$ \\
3 & $-1.900^{* * *}$ & $-2.300^{* * *}$ & $-2.051^{* * *}$ & -0.150 \\
& $(0.035)$ & $(0.026)$ & $(0.083)$ & $(0.144)$ \\
4 & $-1.856^{* * *}$ & $-2.284^{* * *}$ & $1.707^{* * *}$ & 0.148 \\
& $(0.030)$ & $(0.022)$ & $(0.065)$ & $(0.142)$ \\
5 & $-1.915^{* * *}$ & $-2.153^{* * *}$ & $-1.914^{* * *}$ & 0.001 \\
& $(0.023)$ & $(0.023)$ & $(0.048)$ & $(0.089)$ \\
6 & $-1.846^{* * *}$ & $-1.980^{* * *}$ & $-2.004^{* * *}$ & $-0.158^{* *}$ \\
& $(0.031)$ & $(0.026)$ & $(0.035)$ & $(0.078)$ \\
7 & $-1.689^{* * *}$ & $-1.861^{* * *}$ & $-1.966^{* * *}$ & $-0.277^{* * *}$ \\
& $(0.023)$ & $(0.022)$ & $(0.037)$ & $(0.085)$ \\
8 & $-1.660^{* * *}$ & $-1.801^{* * *}$ & $-1.927^{* * *}$ & $-0.267^{* * *}$ \\
& $(0.024)$ & $(0.019)$ & $(0.043)$ & $(0.089)$ \\
& $-1.559^{* * *}$ & $-1.664^{* * *}$ & $-1.926^{* * *}$ & $-0.367^{* * *}$ \\
& $(0.034)$ & $(0.018)$ & $(-.032)$ & $(0.086)$ \\
& $-1.311^{* * *}$ & $-1.344^{* * *}$ & $-1.633^{* * *}$ & $-0.321^{* * *}$ \\
& $(0.049)$ & $(0.018)$ & $(0.035)$ & $(0.105)$ \\
\hline
\end{tabular}

Notes: All control variables are included in the regressions. Standard errors are shown in the parentheses (100 bootstrap replications for the quantile difference results). Asterisks denote significance at the $1 \%(* * *), 5 \%(* *)$, and $10 \%(*)$ levels. 
For a clearer illustration of these estimates, consider Figure 6 which shows the estimated conditional density functions of effective tax rates for properties sold in 1994 or earlier, sold in 2000, and sold in 2008 for each SEV decile. Consistent with the variance results shown in Table 8 , the first two deciles have a greater variance as the years of ownership increase, whereas the variance narrows in the last five property value deciles. Figure 6 highlights two dimensions of the horizontal inequity created by the assessment growth cap: 1) not all property value groups experience the same degree of effective tax rate reductions; and 2) among similarly valued properties sold in the same year, effective tax rates vary widely and the assessment growth limit creates greater variance in effective tax rates for deciles one and two, and more narrow variances in effective tax rates for deciles six through ten. The second result also illustrates the nature of how the OLS estimates were derived. The OLS results for the first decile indicate an average reduction of 12.7 mills for properties fully benefitting from the taxable value cap. As the graph in Figure 6 shows, this result is due primarily to an increased variance since only a small proportion of properties actually receive any effective tax rate reduction. In contrast, deciles two and three experience large location shifts (leftward), with a large proportion of properties having similar effective tax rates as properties recently sold (as shown by the overlapping area between 1994 and 2008), but deciles six through ten experience smaller location shifts with fewer properties receiving little to no benefit from the taxable value cap. Finally, although years of ownership results in distributional shifts across all deciles, note also that the variance of properties tends to narrow as the number of years of ownership increases for the higher valued properties. 
Figure 6: Effect of the Assessment Growth Cap on Horizontal Equity by Decile (SEV)
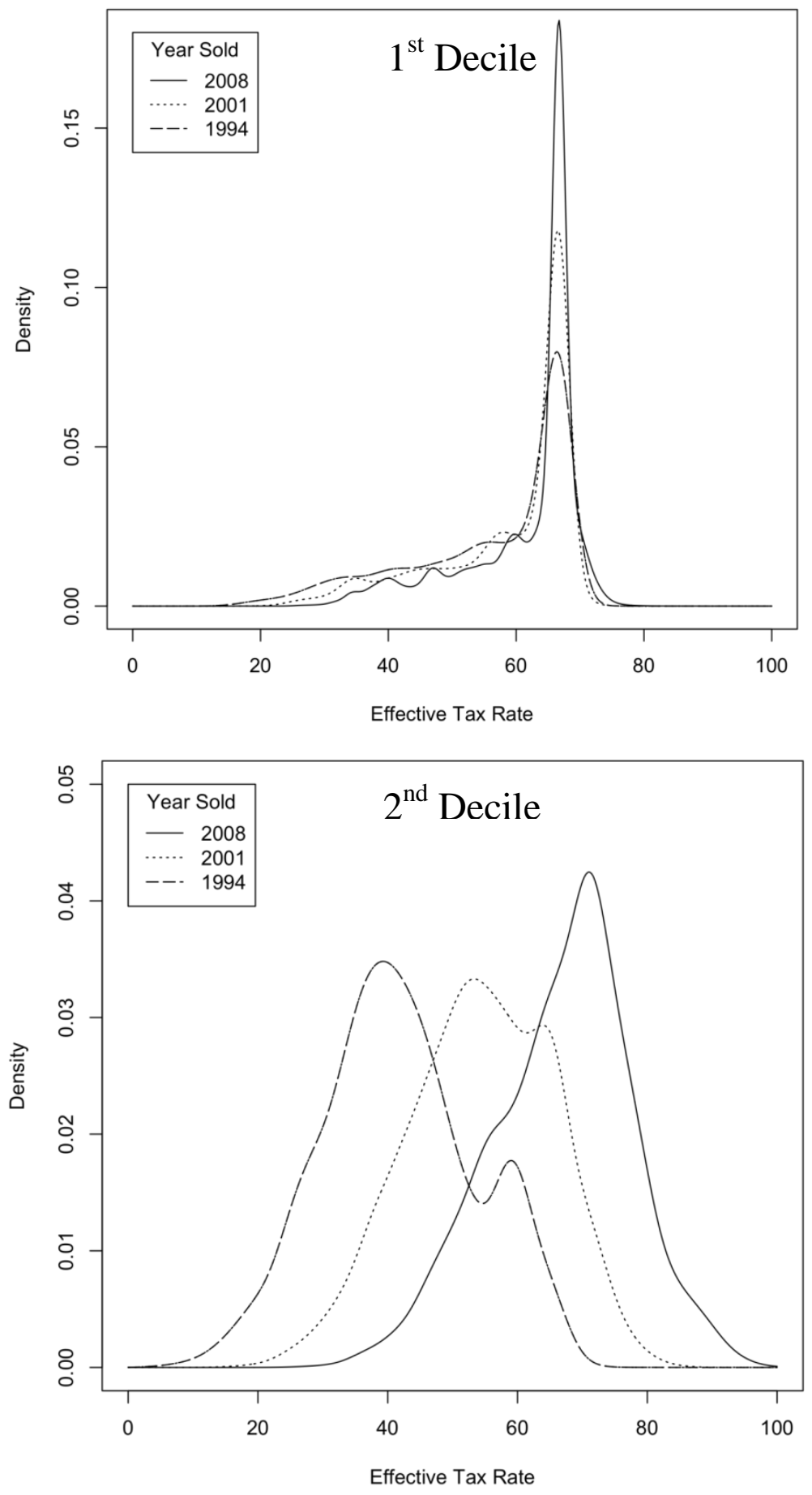
Figure 6: (continued)
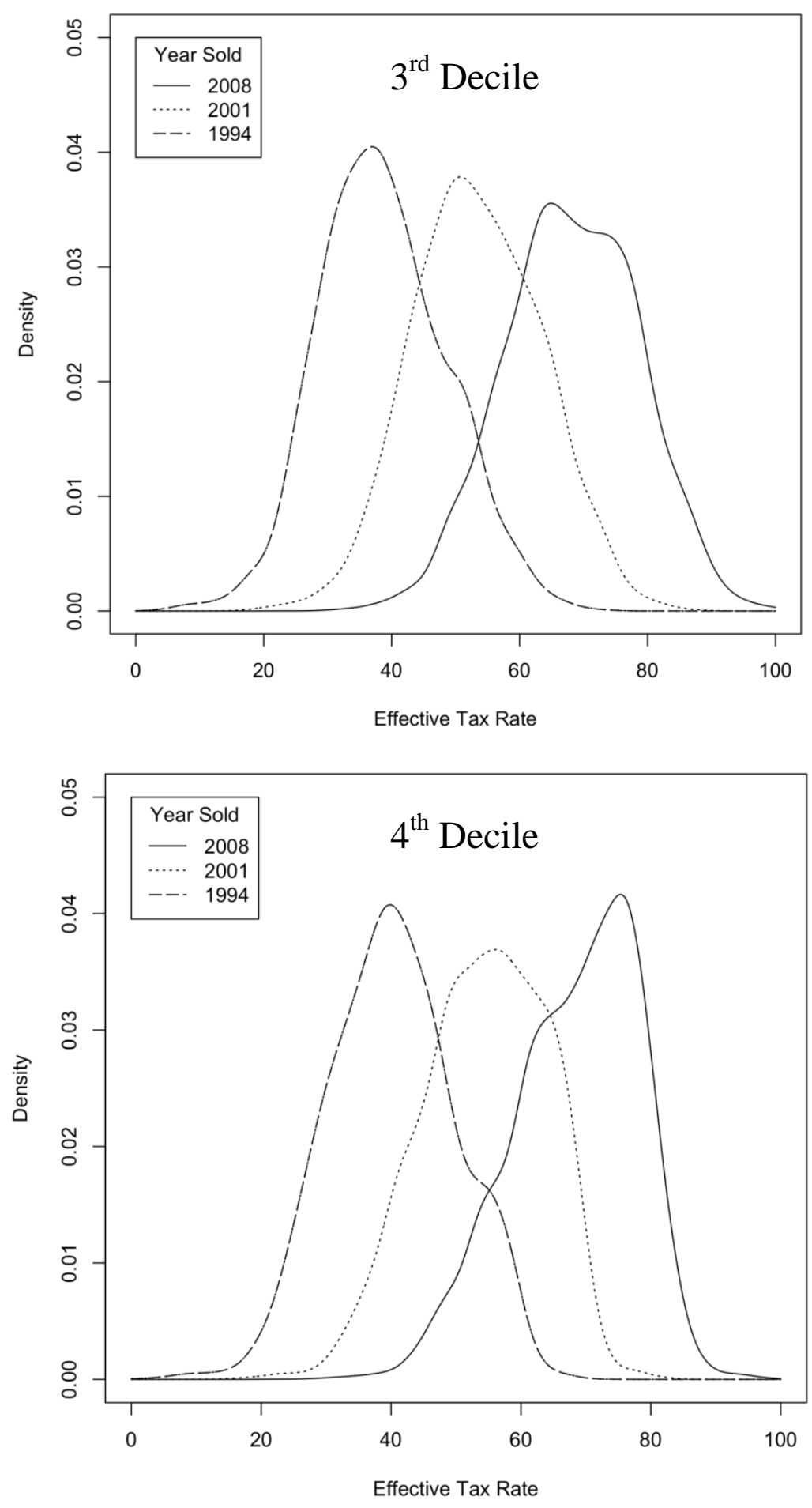
Figure 6: (continued)
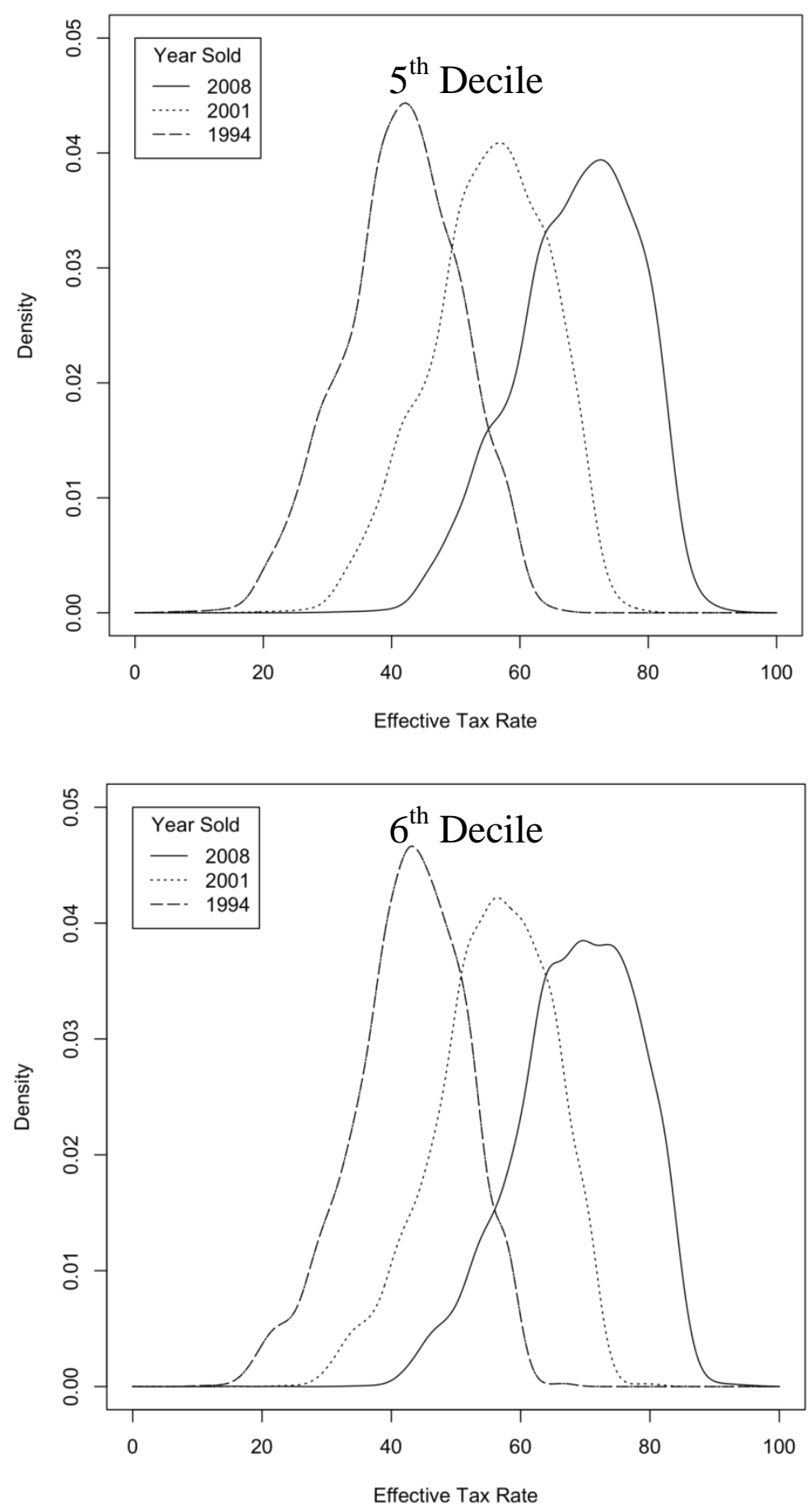
Figure 6: (continued)
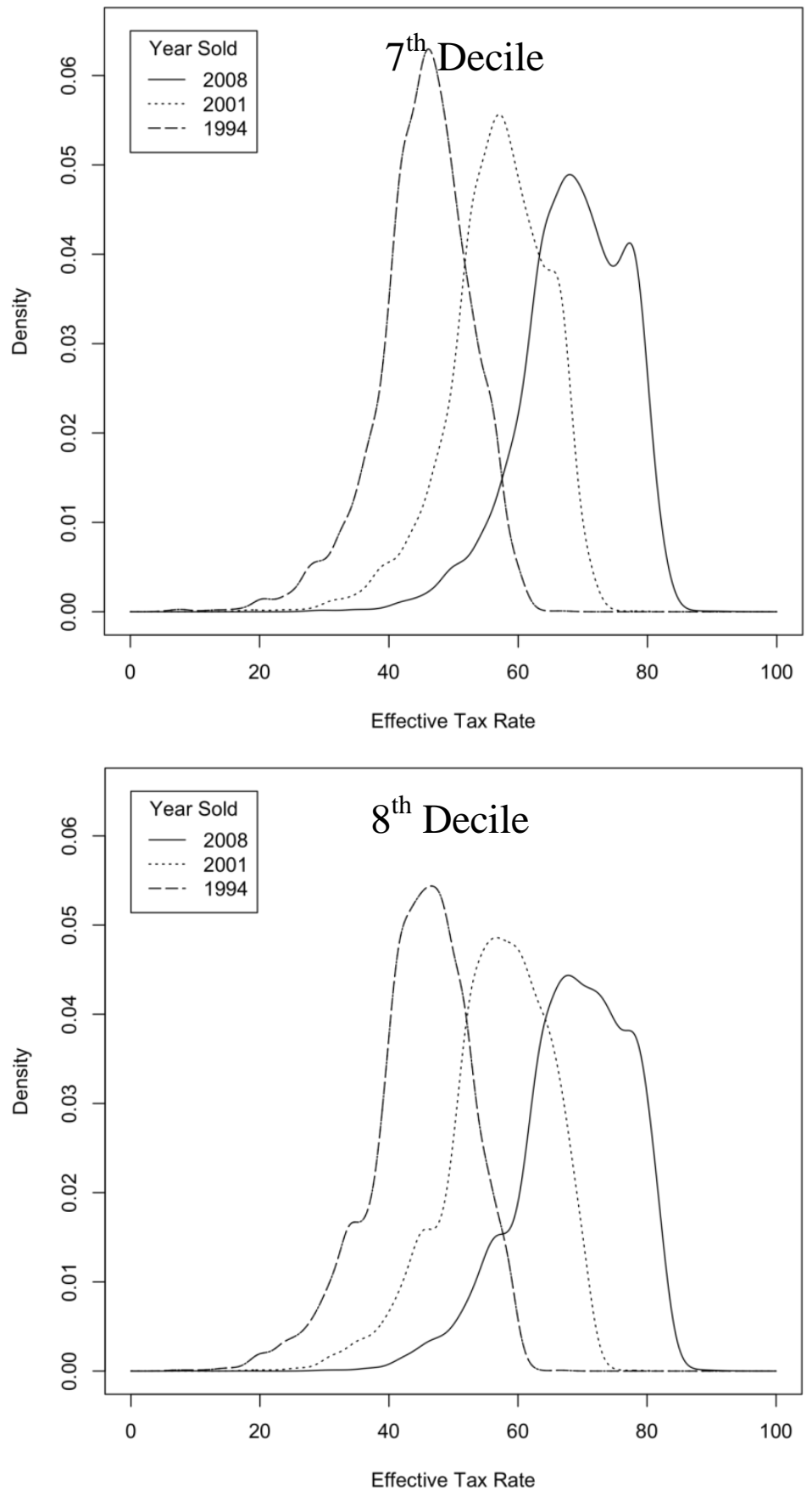
Figure 6: (continued)
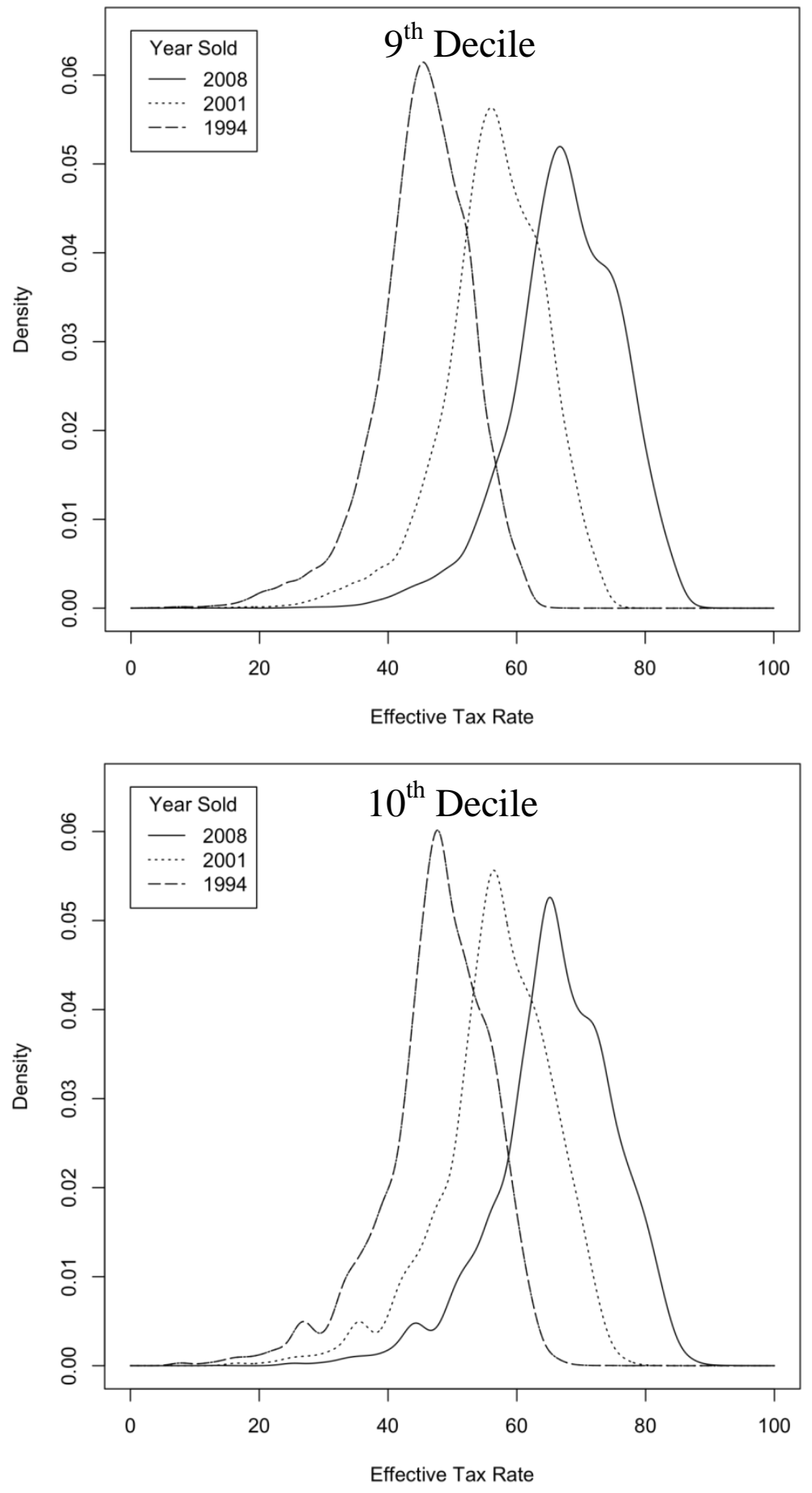


\subsection{Quantile Regression Analysis: Vertical Inequity}

To examine vertical inequity, consider how the distributions differ across property value groups. Figure 7 presents the estimated conditional density functions of effective tax rates for properties sold in 1994 or earlier across selected SEV deciles. ${ }^{33}$ The results highlighted by Figure 7 are similar to the OLS results previously discussed. The third decile receives the largest benefit from the assessment growth cap, the first decile receives the smallest benefit, and the remaining deciles are somewhere in between. That is, the assessment growth cap is regressive across deciles one through three and then progressive across deciles three through ten. Figure 7 offers additional insight not provided by the OLS analysis; high priced properties have less variability in effective tax rates (are more horizontally equitable), whereas low priced properties have greater variability, holding other factors constant. In summary, the observed changes in effective tax rates (non-parallel shifts) revealed with quantile regression techniques are difficult to predict a priori, and would therefore be difficult to model with standard regression techniques.

\footnotetext{
${ }^{33}$ Not all deciles are included because they would clutter the graphs beyond interpretation. Deciles four and five are between three and six and deciles seven through nine are between six and ten.
} 
Figure 7: Effect of Assesment Growth Cap on Vertical Equity
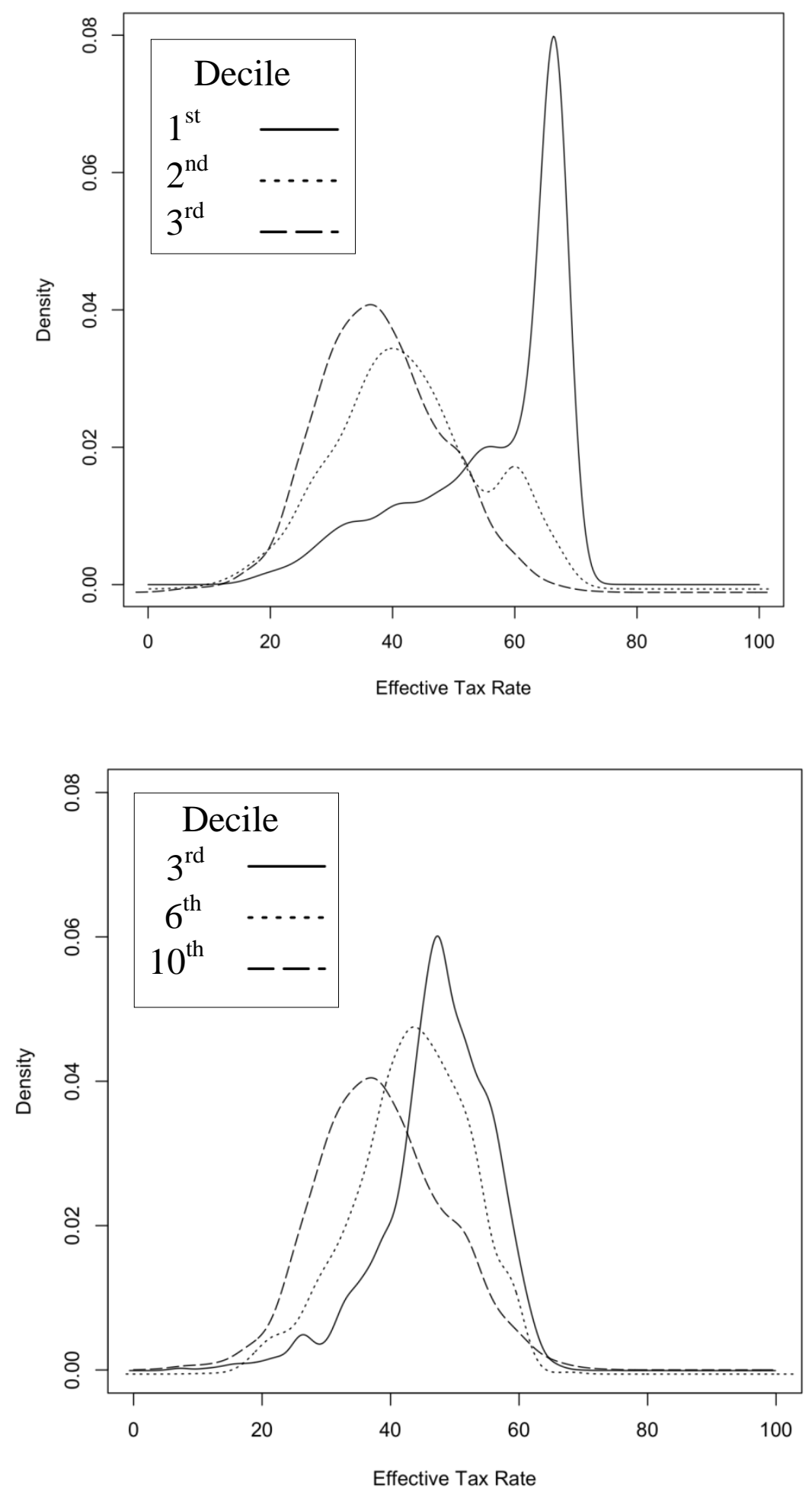


\section{CONCLUSION}

This study offers a new evaluation of the degree of inequity that has been created by Michigan's assessment growth limit. Using parcel level data from the City of Detroit, quantile regression analysis is used to assess the degree of inequity that has been created across homeowners. Our evaluation of horizontal equity indicates that those who have lived in their homes since 1994 or earlier, face effective property tax rates that are between 19 and 52 percent lower than effective rates faced by new homebuyers, all else equal. These rates are even lower for properties that qualify for the Neighborhood Enterprise Zones program. Use of quantile regression techniques offers a clear evaluation of how the assessment growth cap violates the principle of horizontal equity. In addition, our analysis shows how the assessment growth cap generates significant vertical inequity; properties that are nearly half as valuable pay as much as 8 percent higher effective tax rates. Perhaps more importantly, the analysis reveals how the assessment growth cap leads to non-linearities in effective tax rates across property value groups. One could make arguments for more or less progressivity in effective tax rates across the property value groups, but it is difficult to justify a non-linear tax burden distribution. Finally, Michigan's assessment growth limit has created non-uniform changes to effective tax rate distributions; effective tax rates in some property value groups become more variable and others less - a result that was both unknown and difficult to predict without quantile regression techniques.

Our evaluation demonstrates clear violations of the principles of horizontal and vertical equity. Are there any politically feasible approaches that would improve property tax policy outcomes? One proposal would be to permanently eliminate the taxable value cap for new homebuyers, while retaining the cap for existing property owners until the property is sold. Such 
a proposal would allow the tax base to broaden with property turnover and as local housing markets regain value. Over time, horizontal and vertical inequities resulting from the assessment growth cap would diminish. This proposal may be able to garner the political support required to alter property tax policies because it insures that longtime property owners would not experience a sudden increase in tax burden as a result of the elimination of the taxable value cap. Further, as the tax base broadens and property values increase, an already existing property tax revenue growth limit known as the Headlee Amendment (see Skidmore, Ballard and Hodge, 2010 for a brief discussion) provides purchasers of property with protection against substantial tax payment increases, but in a way that avoids the inequities resulting from the assessment growth cap. Haveman and Sexton (2008) recommend alternative property tax relief measures, such as circuitbreaker programs, partial exemptions on owner-occupied housing, and property tax deferral options. Each of these alternative tax-relief measures is already in place in Michigan, in one form or another. If the taxable value cap were to be removed, these other provisions of Michigan property tax law along with other existing property tax-revenue growth limits could provide adequate checks against excessive growth of property tax payments in the future. 


\section{References}

Anderson, Nathan B., and Therese J. McGuire, 2007. "An Unfettered Property Tax in Illinois." Working Paper WP07NA2. Lincoln Institute of Land Policy, Cambridge, MA.

Bowman, John H., 2006. "Property Tax Policy Responses to Rapidly Rising Home Values: District of Columbia, Maryland, and Virginia." National Tax Journal 59 (3), 717-733.

Buchinsky, Moshe. 1994. "Changes in the U.S. Wage Structure 1963-1987: Application of Quantile Regression.” Econometrica 62 (2), 405-458.

Buchinsky, Moshe. 1998. "Recent Advances in Quantile Regression Models: A Practical Guideline for Empirical Research.” Journal of Human Resources 33 (1), 88-126.

Dye, Richard F., Therese J. McGuire, and Daniel P. McMillan. 2005. "Are Property Tax Limitations More Binding Over Time?” National Tax Journal 58 (2), 215-25.

Dye, Richard F., Daniel P. McMillen, and David F. Merriman. 2006. "Illinois' Response to Rising Residential Property Values: An Assessment Growth Cap in Cook County." National Tax Journal 59 (3), 707-16.

Feldman, Naomi E., Paul N. Courant, and Douglas C. Drake, 2003. "The Property Tax in Michigan.” In Ballard, Charles L., Paul N. Courant, Douglas C. Drake, Ronald C. Fisher, and Elisabeth R. Gerber (eds.), Michigan at the Millennium, 577-602. Michigan State University Press, East Lansing, MI.

Giertz, J. Fred, 2006. “The Property Tax Bound.” National Tax Journal 59 (3), 695-705.

Guilfoyle, Jeffrey P., 1998. “The Incidence and Housing Market Effects of Michigan's 1994 School Finance Reforms.” Ph.D. Dissertation. Michigan State University, East Lansing, MI.

Haveman, Mark and Terri A. Sexton. 2008. "Property Tax Assessment Limits: Lessons from Thirty Years of Experience.” Focus Report, Lincoln Institute of Land Policy, Cambridge, MA.

Hao, L. and D.Q. Naiman. 2007. Quantile Regression. Thousand Oaks: Sage Publications.

Koenker, Roger and Gilbert Bassett Jr. 1978. "Regression Quantiles.” Econometrica 46 (1), 33 50.

McMillen, Daniel P. Quantile Regression for Spatial Data. New York: Springer, 2012.

Michigan Department of Treasury. 2011. “Michigan's Taxpayers Guide 2011: Reference for the 2010 Tax Year." Michigan Department of Treasury, Lansing, MI, http://www.legislature.mi.gov/documents/Publications/TaxpayersGuide2011.pdf 
Michigan Department of Treasury. 2010. "Executive Budget Appendix on Tax Credits, Deductions, and Exemptions, Fiscal Year 2010.” Michigan Department of Treasury, Lansing, MI, http://www.michigan.gov/documents/treasury/ExecBudgAppenTaxCreditsDedExemptsF $\underline{\text { Y10_302899_7.pdf }}$

Mikesell, John, and Daniel Mullins. 2008. "The Effects of Property Tax Systems on Household Property Tax Burdens.” State Tax Notes 47 (7), 533-45.

Minnesota Department of Revenue. 2007. Limited Market Value Report: 2006 Assessment Year. Minnesota Department of Revenue, St. Paul, MN, http://taxes.state.mn.us/taxes/legal_policy/research_reports/content/2007_lmv_report.pdf.

Muhammad, Daniel. 2007. "Horizontal Inequity, Vertical Inequity and the District of Columbia's Property Assessment Limitation." Paper presented at the National Tax Association's $100^{\text {th }}$ Annual Conference on Taxation, November 15. Columbus, $\mathrm{OH}$.

Mullins, Daniel R., and Philip G. Joyce, 1996. "Tax and Expenditure Limitations and State and Local Fiscal Structure: An Empirical Analysis.” Public Budgeting and Finance 16 (1), $75-101$.

Richardson, David H., and Richard Thalheimer, 1981. "Measuring the Extent of Property Tax Capitalization for Single Family Residences." Southern Economic Journal 47 (3), 674689.

Skidmore, Mark. 1999. "Tax and Expenditure Limitations and the Fiscal Relationship between State and Local Governments." Public Choice 99 (1-2), 77-102.

Skidmore, Mark, Charles L. Ballard, and Timothy R. Hodge. 2010. "Property Value Assessment Growth Limits and Redistribution of Property Tax Payments: Evidence from Michigan." National Tax Journal 63 (3), 509-38.

Skidmore, Mark, and Mehmet S. Tosun. 2011. "Property Value Assessment Growth Limits, Tax Base Erosion, and Regional In-Migration," Public Finance Review, vol. 39(2), pages 256-287, March.

Youngman, Joan M., 2007. "The Variety of Property Tax Limits: Goals, Consequences, and Alternatives." State Tax Notes 46 (8), 541-557. 